\title{
EXTRACARDIAC FONTAN OPERATION FOR COMPLEX CARDIAC ANOMALIES: SEVEN YEARS' EXPERIENCE
}

Antonio Amodeo, MD

Lorenzo Galletti, MD*

Stefano Marianeschi, MD

Sergio Picardo, MD

Salvatore Giannico, MD

Paolo Di Renzi, MD**

Carlo Marcelletti, MD
Methods: Between 1988 and 1995, 60 patients with complex cardiac anomalies underwent a total extracardiac cavopulmonary connection, a combination of a bidirectional cavopulmonary anastomosis with an extracardiac conduit interposition between the inferior vena cava and pulmonary arteries, except in one patient in whom direct anastomosis was possible. In 40 patients the total extracardiac cavopulmonary connection followed preliminary bidirectional cavopulmonary anastomosis, associated with a modified Damus-Kaye-Stansel anastomosis in 16. The conduits were constructed of Dacron fabric $(n=34)$, homografts $(n=3)$, and polytetrafluoroethylene $(n=22)$. Results: Total early failure rate was $15 \%(n=9)$. Six patients died, and three more had conduit takedown owing to pulmonary artery stenosis and hypoplasia $(n=2)$ and severe atrioventricular valve regurgitation $(n=1)$. Two other patients required anastomosis revision owing to stricture. In a mean follow-up of 48 months (6 to 86 monthe) there were no late deaths (actuarial 5-year survival $88 \% \pm 4 \%$ ); 52 of 54 patients are in New York Heart Association class I or II. Two patients required pulmonary artery balloon dilation or stent implantation, or both, after total extracardiac cavopulmonary connection. Late tachyarrhythmias were detected in four of 54 patients: two had sick sinus syndrome with flutter necessitating a pacemaker implantation and two had recurrent flutter (actuarial 5-year arrhythmia-free rate $92 \% \pm 4 \%$ ). Conduit patency was evaluated by serial magnetic resonance imaging studies. Preliminary data showed a $17.8 \% \pm 7.6 \%$ mean reduction in conduit internal diameter during the first 6 months after total extracardiac cavopulmonary connection, with no progression over the next 5 years. Conclusion: These results demonstrate that the total extracardiac cavopulmonary connection provides good early and midterm results and may reduce the prevalence of late arrhythmias in patients undergoing the Fontan operation. (J Thorac Cardiovase Surg 1997;114:1020-31)
From the Dipartimento Medico-Chirurgico di Cardiologia Pediatrica, Ospedale "Bambino Gesù," Rome, Italy.

Read at the Seventy-sixth Annual Meeting of The American Association for Thoracic Surgery, San Diego, Calif., April 28-May 1, 1996.

Received for publication May 1, 1996; revisions requested June 21, 1996; revisions received June 6, 1997; accepted for publication June 6, 1997.

Address for reprints: Antonio Amodeo, MD, Dipartimento Medico-Chirurgico di Cardiologia Pediatrica, Ospedale Bambino Gesù, Piazza S. Onofrio 4, 00165, Roma, Italy.

*Present address: Hopital "Marie Lannelongue," Plessis Robinson, France.

**Department of Radiology, University of Aquila, L'Aquila, Italy.

Copyright (C) 1997 by Mosby-Year Book, Inc.

$0022-5223 / 97 \$ 5.00+0 \quad \mathbf{1 2 / 6 / 8 3 9 0 4}$
The concept of bypassing the right ventricle was proposed by Rodbard and Wagner ${ }^{1}$ in 1949 . In 1951 Carlon, Mondini, and de Marchi ${ }^{2}$ experimentally proved that the lungs could be perfused under venous pressure, and in 1958 Glenn $^{3}$ reported the first clinically successful anastomosis between the superior vena cava and the right pulmonary artery. Anastomoses between the inferior vena cava (IVC) and right pulmonary artery were also performed experimentally, but it was not until 1971 that Fontan and associates ${ }^{4}$ reported the first successful total venous diversion to the lungs in a patient with tricuspid atresia. Since this original description, a number of modification to Fontan's operation have been described, which have simplified the operation and allowed its application to a variety of complex 
Table I. Preoperative diagnosis

\begin{tabular}{|c|c|c|c|c|c|}
\hline Diagnostic group & No. of patients & Deaths & Takedown & Global failure & Percent \\
\hline $\begin{array}{l}\text { SV with LAVV hypopla- } \\
\text { sia or atresia }\end{array}$ & 26 & 3 & 0 & 3 & 11 \\
\hline Heterotaxy syndrome & 12 & 3 & 2 & 5 & $41(p=0.01)$ \\
\hline Criss-cross hearts & 6 & 0 & 0 & 0 & 0 \\
\hline CAVC: & 6 & 0 & 0 & 0 & 0 \\
\hline (unbalanced CAVC) & 2 & & & & \\
\hline (DORV, CAVC) & 4 & & & & \\
\hline SV with LA juxtaposition & 3 & 0 & 0 & 0 & 0 \\
\hline $\begin{array}{l}\text { CCA with situs solitus } \\
\text { and dextrocardia }\end{array}$ & 7 & 0 & 1 & 1 & 14 \\
\hline Total & 60 & 6 & 3 & 9 & 15 \\
\hline
\end{tabular}

$S V$, Single ventricle; $L A V V$, left atrioventricular valve; $C A V C$, common atrioventricular canal; $D O R V$, double-outlet right ventricle; $L A$, left atrial; $C C A$, complex cardiac anomalies.

cardiac anomalies. Since $1988 \mathrm{we}^{5}$ have used a procedure conceptually derived from the intraatrial tunnel approach reported by de Leval and colleagues ${ }^{6}$ and by Jonas and Castaneda. ${ }^{7}$ This consists of an extracardiac conduit placed between the IVC and the pulmonary artery associated with a bidirectional cavopulmonary anastomosis, so-called total extracardiac cavopulmonary connection (TECC). Our purpose is to review the first 7 years of experience with TECC in complex cardiac anomalies.

\section{Patients and methods}

Patient population. Between November 1988 and June 1995, 60 patients with complex cardiac anomalies underwent a modified Fontan operation by TECC. Preoperative diagnoses are grouped into six different categories and are listed in Table I. Fifty-five $(91 \%)$ patients had previously undergone a total of 103 palliative operations before TECC, as shown in Figs. 1 and 2. Anomalies of systemic or pulmonary venous return (or both) were present in 27 patients; six of them had total anomalous pulmonary venous connection (1 infradiaphragmatic, 1 supracardiac, and 4 intracardiac). In 38 patients the repair was staged by preliminary bidirectional cavopulmonary anastomosis (BCPA) that was bilateral in eight patients and associated with a modified Damus-Kaye-Stansel procedure to bypass a subaortic obstruction in 16 patients. Two additional patients had a BCPA resulting from takedown of a previous Fontan shunt. Age and weight at operation averaged $73 \pm 35$ months (18 to 219 months) and $21 \pm 10.7 \mathrm{~kg}$ (10 to $73 \mathrm{~kg}$ ); 16 patients were younger than 4 years at operation. Mean pulmonary artery pressure was $12 \pm 4 \mathrm{~mm} \mathrm{Hg}$ (range 4 to 24 $\mathrm{mm} \mathrm{Hg}$, mean arterial oxygen saturation $82 \% \pm 7.5 \%$ (range $51 \%$ to $95 \%$ ), and mean end-diastolic ventricular pressure $8 \pm 3 \mathrm{~mm} \mathrm{Hg}$ (range 2 to $16 \mathrm{~mm} \mathrm{Hg}$ ). Mean hematocrit value was $51.6 \% \pm 6.4 \%(41 \%$ to $68 \%)$ and hemoglobin content $16.4 \pm 1.8 \mathrm{gm} / \mathrm{dl}(12.4$ to $19.8 \mathrm{gm} / \mathrm{dl})$.

Surgical technique. After median sternotomy, cardiopulmonary bypass was instituted by a single atrial cannula in 49 patients, by the IVC and common atrium in 3, and by double caval cannulation in the other 8 . Deep hypothermic circulatory arrest was used in 56 patients primarily to simplify the operation in patients who had had multiple previous interventions. No particular difficulties in venous drainage related to use of a single "left atrial" cannula during rewarming with the heart-lung machine were observed. In our recent experience ( 4 patients) the TECC was performed without aortic crossclamping by placement of a right-angled cannula in the most proximal part of the intrathoracic IVC. Thirty-six patients received crystalloid cardioplegia and 20 patients had blood cardioplegia. As previously reported, ${ }^{5}$ a conduit segment is inserted after wide mobilization of the IVC and pulmonary arteries. The conduit was of woven Dacron fabric in 33 patients, polytetrafluoroethylene in 23 , and nonvalved homograft in 3 ; the size was selected in relation to patient weight (Fig. 3). In one case of heterotaxy with interrupted IVC and azygos continuation, the conduit diverted only the hepatic venous blood to the pulmonary artery. In one patient with tricuspid atresia, transposition of the great arteries, and left appendage juxtaposition, a direct anastomosis between the IVC and the pulmonary artery was possible. Atrial septectomy, when required, was performed through the atrial stump of the transected IVC. Thirty-three associated procedures to TECC were performed (Table II). The mean aortic crossclamp time was 37 minutes (range 15 to 72 minutes). The IVC-pulmonary artery connection was right-sided in 57 cases and leftsided in three.

Data analysis. Data were analyzed and mean \pm standard deviation of numeric values are presented. Association between the outcome events (death or failure) and preoperative and operative variables were analyzed univariately by $\chi^{2}$ or Fisher's exact test. Follow-up information was obtained in all patients by outpatient assessment or contact with primary physicians. Echocardiography, 12-lead surface electrocardiograms, and 24-hour ambulatory electrocardiographic monitoring were part of the yearly follow-up evaluation of all patients. Care was taken to monitor patients in whom clinical follow-up suggested an arrhythmia. Survival data and survival probability of time-related events were analyzed by the method of Kaplan and Meier. In 30 patients 60 magnetic resonance imaging studies were performed by means of a 0.2 -tesla permanent magnet (Esaote MP 4000, Esaote Spa, Genova, Italy). Spin echo (TR $=$ RR ECG interval, $\mathrm{TE}=$ 


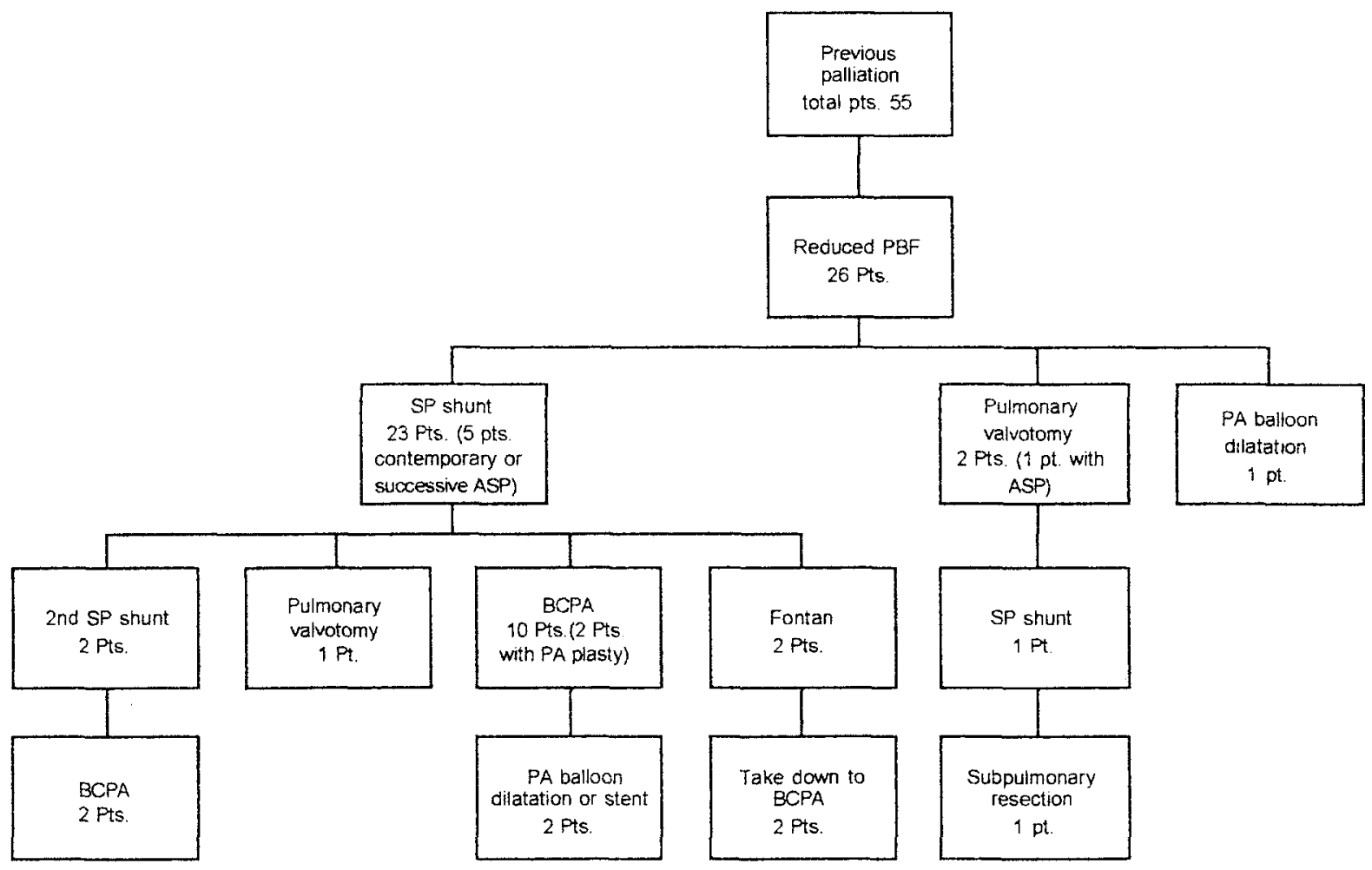

Fig. 1. Previous palliative operation in patients with reduced pulmonary blood flow $(P B F)$. $A S P$, Atrial septectomy; $S P$, systemic-pulmonary; $P A$, pulmonary artery; $B C P A$, bidirectional cavopulmonary anastomosis.

$25 \mathrm{msec}$ slice thickness often interfaced) sequences on axial, sagittal, and coronal planes were used to assess complete visualization of the prosthetic tube. In case of suspected parietal thrombosis, gradient repasing sequences (TR $=$ RR ECG interval, $\mathrm{TE}=23 \mathrm{msec}$ flip angle 45 degrees) were used to decrease flow artifacts. To evaluate the mean percentual decrease in tube diameter, we obtained the average of 10 to 20 diameter measurements in all planes. Furthermore, different points of maximal diameter decrease eventually present (proximal and distal anastomoses as well as third medium of the tube) were also evaluated. The examination time was 35 to 60 minutes for each patient.

\section{Results}

Early results. Six hospital deaths occurred (10\%) and the extracardiac conduit was taken down in three additional patients, for a total early failure rate of $15 \%$ (Table III). The cause of death was myocardial in four patients, all of whom had a combination of ventricular pressure or volume overload with myocardial hypertrophy before TECC. Pulmonary artery distortion or hypoplasia appeared to be the cause of death in two patients and of failure in an additional two. In the last patient, failure was mainly the result of atrioventricular valve regurgitation. Most of the patients received inotropic agents in the immediate postoperative period. The mean duration of mechanical ventilation was 24.8 hours (range 1 to 96 hours), excluding seven patients in whom ventilatory support was prolonged $(>100$ hours). Mean arterial oxygen saturation in room air at discharge was $94 \%$ (range $88 \%$ to $99 \%$ ). Prolonged pleural and peritoneal effusions, defined as more than 10 days of drainage or need for multiple drainage procedures, occurred in 18 patients (33\%). Two patients underwent early surgical revision of a stenotic anastomosis, between the superior vena cava and pulmonary artery in one and between the IVC and the conduit in the other. Two others underwent plication of a hemidiaphragm owing to phrenic nerve injury (bilateral in 1): all these patients had multiple palliative procedures before the TECC operation. Mediastinitis developed in three patients. All patients were discharged receiving warfarin therapy for at least 6 months and 


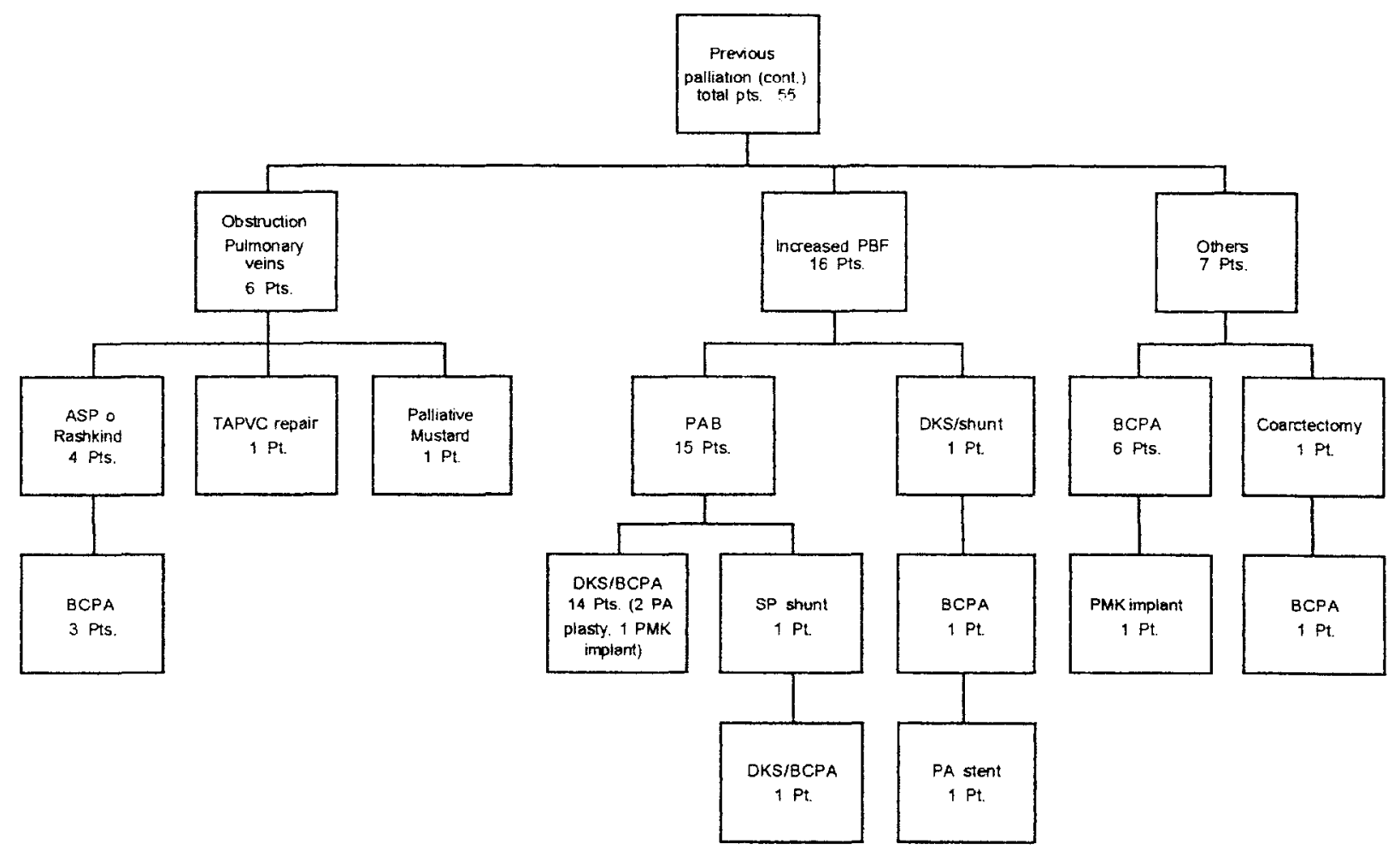

Fig. 2. Previous palliative operation (excluded patients with reduced pulmonary blood flow $[P B F]$ ). $A S P$, Atrial septectomy; $T A P V C$, total anomalous pulmonary venous connection; $B C P A$, bidirectional cavopulmonary anastomosis; $P A B$, pulmonary artery banding; $D K S$, Damus-Kaye-Stansel; $P A$, pulmonary artery; $S P$, systemic-pulmonary; $P M K$, pacemaker.

then aspirin. In the follow-up period, neither thromboembolic nor bleeding complications occurred during warfarin therapy. Statistical analysis (Table IV) revealed that heterotaxy syndrome, total anomalous pulmonary venous connection, previous palliative operation to increase pulmonary blood flow, and operation done during years 1992 to 1993 proved to be risk factors for death or takedown. Atrioventricular valve regurgitation ( 2 patients) and pulmonary artery distortion (4 patients), although apparent causes of failure in these patients, approached but did not reach statistical significance. Age less than 4 years did not prove to be a risk factor for death or takedown.

Late results. Follow-up to December 1995 was available in all 54 surviving patients. There were no late deaths, for an actuarial survival at 5 years of $88 \% \pm 4 \%$ (Fig. 4). At a mean follow-up of $483 \pm$ 24.7 months (range 6 to 86 months), 50 patients (92\%) were in New York Heart Association functional class I, two in class II, and two in class III owing to moderate to severe atrioventricular valve regurgitation. Echocardiography showed normal systolic ventricular function in 49 patients. Thirtyone patients had reduced effort tolerance ( $60 \%$ to $70 \%$ of normal age capacity) at the treadmill test performed 1 year after the operation. The three patients in whom the repair was taken down have remained cyanotic and have markedly reduced effort tolerance; they are now scheduled for a new TECC completion. Two patients underwent balloon dilatation of a stenotic superior cavopulmonary anastomosis and one had a stent placed in the left pulmonary artery. Three patients underwent drainage of a pleural and pericardial effusion 2 months after the operation, and two others had replacement of a malfunctioning pacemaker. One patient required device closure of a residual patent Blalock-Taussig shunt. Eighty-three percent of patients are free from reoperation at 5 years (Fig. 5). Although no routine neurologic examinations were done in these patients, to the best of our knowledge no obvious 


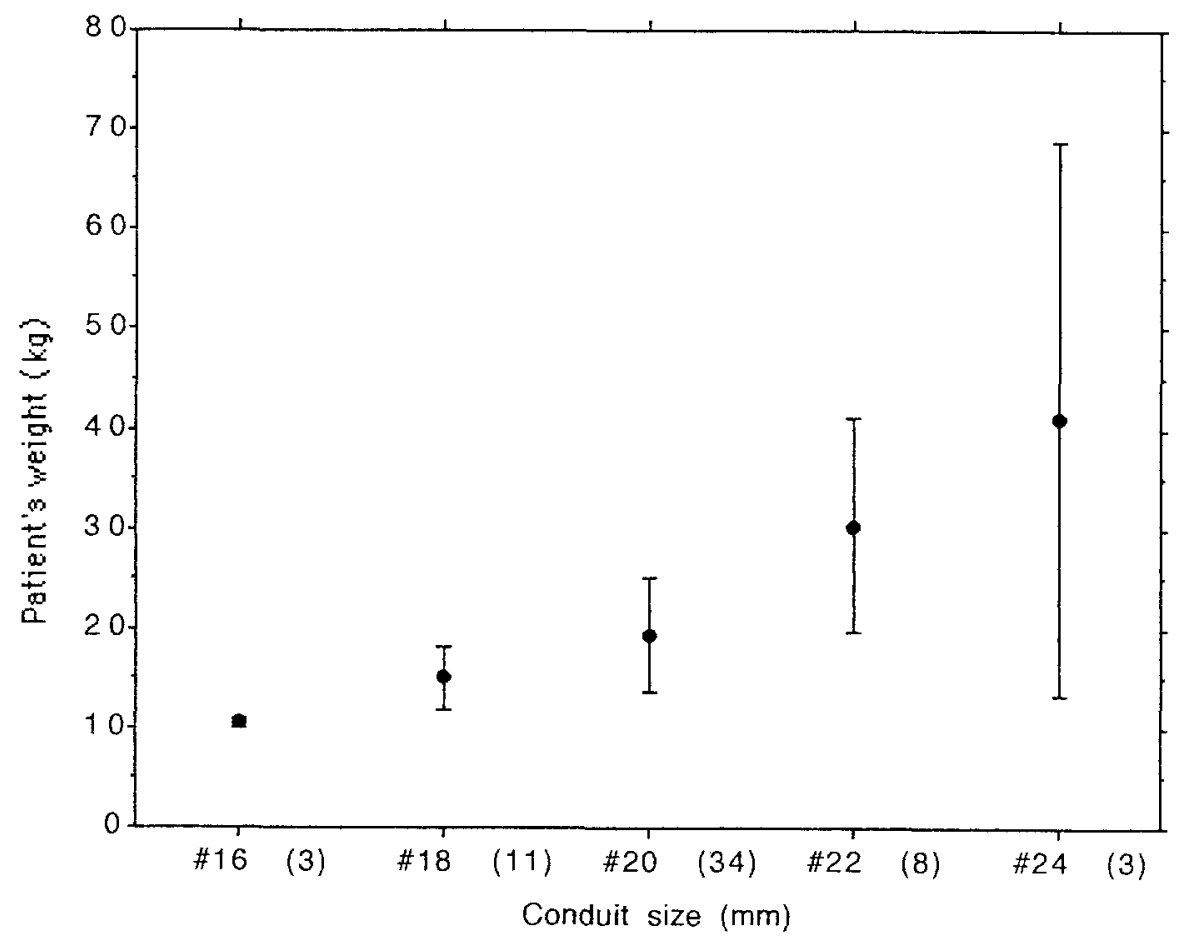

Fig. 3. Relationship between patient's weight and conduit size (patient's number in parentheses). Error bars indicate 1 standard deviation.

Table II. Associate procedures to TECC

\begin{tabular}{lr}
\hline & No. \\
\hline Atrial septectony & 15 \\
PA plasty & 9 \\
PMK implantation & 6 \\
TAPVC repair & 1 \\
AVV repair & 1 \\
PMK substitution & 1 \\
Total & 33 \\
\hline
\end{tabular}

$P A$, Pulmonary artery; $P M K$, pacemaker; $T A P V C$, total anomalous pulmonary venous connection; $A V V$, atrioventricular valve.

neurologic complications occurred in the follow-up period.

\section{Arrhythmias}

Preoperative arrhythmias. A permanent pacemaker had been implanted in two patients before TECC because of congenital complete atrioventricular block. Pacemaker implantation was performed as an additional procedure to TECC in six patients for congenital complete atrioventricular block (4 patients), sinoatrial block ( 1 patient), and sinus node dysfunction caused by a previous palliative Mustard operation (1 patient).
Perioperative arrhythmias. Perioperative arrhythmias (less than 30 days after the Fontan operation) were observed in 13 patients. Nine patients had transient junctional rhythm with no hemodynamic consequences.

Three patients had atrial flutter and underwent electrical cardioversion. One patient had junctional ectopic tachycardia that responded to antiarrhythmic drugs. None of these patients had arrhythmias at the time of hospital discharge.

Major late postoperative arrhythmias (more than 30 days after the Fontan procedure) occurred in four patients. All of them had recurrent atrial flutter (triggered by effort in one): two of the four patients are receiving antiarrhythmic drugs, and the other two, in whom the flutter was associated with symptomatic bradycardia (sick sinus syndrome), were treated by pacemaker implantation. Consequently, 92.6\% of patients are free from major arrhythmias 5 years after the TECC (Fig. 6). Two additional patients had what we considered minor episodes of supraventricular or unifocal ventricular ectopy discovered by Holter monitoring. Preliminary results of transesophageal atrial pacing study, performed 2 years after the TECC operation, showed no inducible atrial 
Table III. Cause of Fontan failure

\begin{tabular}{|c|c|c|c|c|c|}
\hline No. & Preoperative diagnosis & $\begin{array}{l}\text { Age } \\
\text { (mo) }\end{array}$ & Previous palliation & Outcome & Cause \\
\hline 1 & DORV, hypoplastic LV & 39 & $\begin{array}{l}\text { R BT shunt + ASP (10 days) } \\
\text { BCPA + ASP ( } 23 \text { mo })\end{array}$ & Takedown, death & Myocardial failure \\
\hline 2 & Asplenia & 98 & $\begin{array}{l}\text { R BT shunt ( } 15 \text { days) } \\
\text { BCPA ( } 36 \text { mo) }\end{array}$ & Takedown, ECMO, death & Myocardial failure \\
\hline 3 & DORV, hypoplastic LV & 64 & $\begin{array}{l}\text { R BT shunt + ASP (2 mo) } \\
\text { Fontan (APC) (13 mo) } \\
\text { Takedown, BCPA (13 mo) }\end{array}$ & Death & $\begin{array}{l}\text { Myocardial failure, } \\
\text { AVV regurgitation }\end{array}$ \\
\hline 4 & L-UVH, TGA & 141 & $\begin{array}{l}\mathrm{PAB}+\mathrm{ASP}(11 \mathrm{yr}) \\
\mathrm{DKS}+\mathrm{BCPA}(12 \mathrm{yr})\end{array}$ & Death & $\begin{array}{l}\text { Myocardial failure, } \\
\text { PVOD? }\end{array}$ \\
\hline 5 & Asplenia & 70 & $\begin{array}{l}\text { R BT shunt ( } 3 \text { days) } \\
\text { BCPA }(15 \mathrm{mo})\end{array}$ & Death & PA stenosis/hypoplasia \\
\hline 6 & Asplenia & 55 & $\begin{array}{l}\text { L BT shunt }(8 \mathrm{mo}) \\
\text { BCPA + PA plasty }(24 \mathrm{mo}) \\
\text { PA balloon dilatation }(48 \mathrm{mo})\end{array}$ & Takedown, ECMO, death & PA stenosis/hypoplasia \\
\hline 7 & Asplenia & 34 & TAPVC repair (1 mo) & Takedown, AVV repair & $\begin{array}{l}\text { AVV regurgitation, } \\
\text { pulmonary veins } \\
\text { obstruction? }\end{array}$ \\
\hline 8 & Asplenia & 98 & $\begin{array}{l}\mathrm{L} \text { BT shunt }(1 \mathrm{mo}) \\
\text { BCPA }(48 \mathrm{mo})\end{array}$ & Takedown, PA plasty & PA stenosis/hypoplasia \\
\hline 9 & $\begin{array}{l}\text { Situs solitus, dextrocardia } \\
\text { (ccTGA, VSD, pulm atresia) }\end{array}$ & 46 & BCPA $(1 \mathrm{mo})$ & Takedown, PA plasty & PA stenosis/hypoplasia \\
\hline
\end{tabular}

DORV, Double-outlet right ventricle; $L V$, left ventricle; $L-U V H$, left univentricular heart; $T G A$, transposition of the great arteries; $c c T G A$, congenitally corrected transposition of the great arteries; $V S D$, ventricular septal defect; $P A$, pulmonary artery; $R$, right; $B T$, Blalock-Taussig; $A S P$, atrial septectomy; $B C P A$, bidirectional cavopulmonary anastomosis; $A P C$, atriopulmonary connection; $P A B$, pulmonary artery banding; $D K S$, Damus-Kaye-Stansel; $L$, left; $T A P V C$, total anomalous pulmonary venous connection; $E C M O$, extracorporeal membrane oxygenation; $A V V$, atrioventricular valve; $P V O D$, pulmonary vascular obstructive disease.

tachycardias among the first nine patients (different from the atriopulmonary connection operation).

Magnetic resonance imaging. The magnetic resonance imaging study showed in 20 patients a mean reduction of the internal conduit diameter of $17.8 \%$ $\pm 7.6 \%$ during the first 6 months with no progression over the following 5 years $(17.2 \% \pm 6.17 \%, p=$ not significant). However, even the maximal internal diameter reduction found in 10 patients did not progress over time $(32 \% \pm 7.9 \%$ vs $32.1 \% \pm 7.9 \%)$. Coronal plane images demonstrated shape modification from circular to elliptic, at some point within the conduit, in these 10 patients.

\section{Discussion}

Since the original report by Fontan, the concept has evolved that energy dissipation should be minimized while caval blood is diverted directly into the pulmonary circuit. de Leval and coworkers ${ }^{6}$ clearly demonstrated that head pressure losses and turbulence across cavities and corners cause significant energy dissipation. These authors therefore concluded that maximal forward output can be achieved by streamlining blood flow through a valveless right atrial tunnel of uniform caliber. In 1988 de Leval and associates ${ }^{6}$ and Jonas and Castaneda ${ }^{7}$ published their clinical experience with total cavopulmonary connection using a technique similar to that previously described by Puga, Chiavarelli, and Hagler. ${ }^{8}$ Associated with these changes in technique, mortality and morbidity have progressively decreased to a present mortality rate for TCPC from $5 \%$ to $15 \% .^{9-12}$ The potential advantages of the TECC modification, as previously reported, ${ }^{5,13}$ include technical ease, no intraatrial manipulation or suture lines near the cavoatrial junction (potentially less arrhythmogenic), and satisfactory hemodynamic results. TECC is particularly useful under anatomic circumstances in which atrial septation can be hazardous, such as in left juxtaposition of the atrial appendages, heterotaxy syndrome with anomalous systemic or pulmonary venous connections (or both), and hypoplasia of the left atrioventricular valve or complete atrioventricular canal. Our results with TECC in complex cardiac anomalies are similar to those of other groups, ${ }^{9-12}$ with an early mortality of $10 \%$. The definition and quantification of risk factors for patients undergoing a Fontan-type repair remain elusive. Our analysis identified heterotaxy syndrome and operations done during the years 1992 and 1993 to be predictive of poor outcome. The high rate of failure in heterotaxy syndrome, 
Table IV. Statistical analysis

\begin{tabular}{|c|c|c|c|c|c|c|c|}
\hline & $\begin{array}{c}\text { No. of } \\
\text { patients }\end{array}$ & $\begin{array}{c}\text { Early } \\
\text { deaths }(\%)\end{array}$ & $95 \% \mathrm{CL}$ & $p$ Value & $\begin{array}{c}\text { Total } \\
\text { failure (\%) }\end{array}$ & $95 \% C L$ & $p$ Value \\
\hline \multicolumn{8}{|l|}{ Age } \\
\hline$<4$ yr & 16 & 6.25 & $0-16$ & \multirow[t]{2}{*}{$p=1$} & 18.7 & $3-34$ & \multirow[t]{2}{*}{$p=0.68$} \\
\hline$>4 \mathrm{yr}$ & 44 & 11.4 & $0-24$ & & 13.6 & $0-27$ & \\
\hline \multicolumn{8}{|l|}{ Heterotaxy } \\
\hline Yes & 12 & 25 & $8-42$ & \multirow{2}{*}{$p=0.08$} & 41.7 & $22-61$ & \multirow[t]{2}{*}{$p=0.01$} \\
\hline No & 48 & 6.25 & $0-16$ & & 8.3 & $0-19$ & \\
\hline \multicolumn{8}{|l|}{ Dextrocardia } \\
\hline Yes & 19 & 5.3 & $0-14$ & \multirow[t]{2}{*}{$p=0.65$} & 21.1 & $5-37$ & \multirow[t]{2}{*}{$p=0.44$} \\
\hline No & 41 & 12.2 & $0-25$ & & 12.2 & $0-25$ & \\
\hline \multicolumn{8}{|l|}{ CAVV } \\
\hline Yes & 17 & 17.6 & $3-33$ & \multirow[t]{2}{*}{$p=0.33$} & 23.5 & $7-40$ & \multirow[t]{2}{*}{$p=0.25$} \\
\hline No & 43 & 7 & $3-17$ & & 11.6 & $0-24$ & \\
\hline \multicolumn{8}{|c|}{ LAVV hypoplasia/atresia } \\
\hline Yes & 30 & 10 & $2-22$ & \multirow[t]{2}{*}{$p=1$} & 10 & $2-22$ & $p=0.30$ \\
\hline No & 30 & 10 & $2-22$ & & 20 & $4-36$ & \\
\hline TAPVC & & & & & & & \\
\hline Yes & 6 & 50 & $30-70$ & $p=0.01$ & 66.7 & $48-85$ & $p=0.003$ \\
\hline No & 54 & 5.6 & $0-15$ & & 9.3 & $0-21$ & \\
\hline SVDA & & & & & & & \\
\hline Yes & 21 & 19 & $4-34$ & $p=0.17$ & 28.6 & $11-46$ & $p=0.05$ \\
\hline No & 39 & 5.1 & $4-14$ & & 7.7 & $3-18$ & \\
\hline Previous SP shu & & & & & & & \\
\hline Yes & 26 & 19.2 & $4-35$ & $p=0.07$ & 23.1 & $7-40$ & $p=0.15$ \\
\hline No & 34 & 2.9 & $0-10$ & & 8.8 & $0-20$ & \\
\hline Previous PAB & & & & & & & \\
\hline Yes & 16 & 6.25 & $0-16$ & $p=1$ & 6.25 & $0-16$ & $p=0.42$ \\
\hline No & 44 & 11.3 & $0-24$ & & 18.1 & $3-33$ & \\
\hline Previous PA pro & & & & & & & \\
\hline Yes & 5 & 20 & $4-36$ & $p=0.42$ & 20 & $4-36$ & $p=0.56$ \\
\hline No & 55 & 9.1 & $0-20$ & & 14.5 & $1-28$ & \\
\hline Previous ASP & & & & & & & \\
\hline Yes & 15 & 6.7 & $0-16$ & $p=1$ & 13.3 & $0-27$ & $p=1$ \\
\hline No & 45 & 11.1 & $0-23$ & & 15.6 & $1-30$ & \\
\hline Previous BCPA & & & & & & & \\
\hline Yes & 40 & 15 & $1-29$ & $p=0.16$ & 20 & $4-36$ & $p=0.24$ \\
\hline No & 20 & 0 & 0 & & 5 & $0-14$ & \\
\hline PA distortion & & & & & & & \\
\hline Yes & 15 & 13.3 & $0-27$ & $p=0.63$ & 26.7 & $9-44$ & $p=0.20$ \\
\hline No & 45 & 8.9 & $0-20$ & & 11.1 & $0-23$ & \\
\hline AVV regurgitati & & & & & & & \\
\hline Yes & 5 & 20 & $4-36$ & $p=0.42$ & 40 & $21-59$ & $p=0.15$ \\
\hline No & 55 & 9.1 & $0-20$ & & 12.7 & $0-26$ & \\
\hline PA pressure & & & & & & & \\
\hline$>15 \mathrm{~mm} \mathrm{Hg}$ & 11 & 18.1 & $3-33$ & $p=0.15$ & 18.1 & $3-33$ & $p=0.49$ \\
\hline$<15 \mathrm{~mm} \mathrm{Hg}$ & 42 & 7.1 & $0-17$ & & 11.9 & $0-25$ & \\
\hline Mịssed & 7 & 14.3 & $1-28$ & & 28.6 & $11-46$ & \\
\hline PA plasty at For & & & & & & & \\
\hline Yes & 10 & 10 & $0-22$ & $p=1$ & 20 & $4-36$ & $p=0.63$ \\
\hline No & 50 & 10 & $2-22$ & & 14 & $0-28$ & \\
\hline Total PA procec & & & & & & & \\
\hline Yes & 13 & 15.4 & $1-30$ & $p=0.60$ & 23.1 & $7-40$ & $p=0.39$ \\
\hline No & 47 & 8.5 & $0-19$ & & 12.7 & $0-26$ & \\
\hline ASP at Fontan & & & & & & & \\
\hline Yes & 16 & 6.25 & $0-16$ & $p=1$ & 12.5 & $0-25$ & $p=1$ \\
\hline No & 44 & 11.4 & $0-24$ & & 15.9 & $2-30$ & \\
\hline Total ASP & & & & & & & \\
\hline Yes & 28 & 7.1 & $0-17$ & $p=0.67$ & 10.7 & $0-23$ & $p=0.48$ \\
\hline No & 32 & 12.5 & $0-25$ & & 18.7 & $3-34$ & \\
\hline Years of operat & & & & & & & \\
\hline $1989-1991$ & 28 & 3.5 & $4-11$ & & 10.7 & $0-23$ & \\
\hline $1992-1993$ & 12 & 33.3 & $15-52$ & $p=0.01$ & 33.3 & $15-52$ & $p=0.01$ \\
\hline $1994-1995$ & 20 & 5 & $0-14$ & & 10 & $0-22$ & \\
\hline
\end{tabular}

$C L$, Confidence limits; $C A V V$, common atrioventricular valve; $L A V V$, left atrioventricular valve; TAPVC, total anomalous pulmonary venous connection; $S V D A$, systemic venous drainage anomalies; $S P$, systemic-pulmonary; $P A B$, pulmonary artery banding; $P A$, pulmonary artery; $A S P$, atrial septectomy; $B C P A$, bidirectional cavopulmonary anastomosis; $A V V$, atrioventricular valve. 


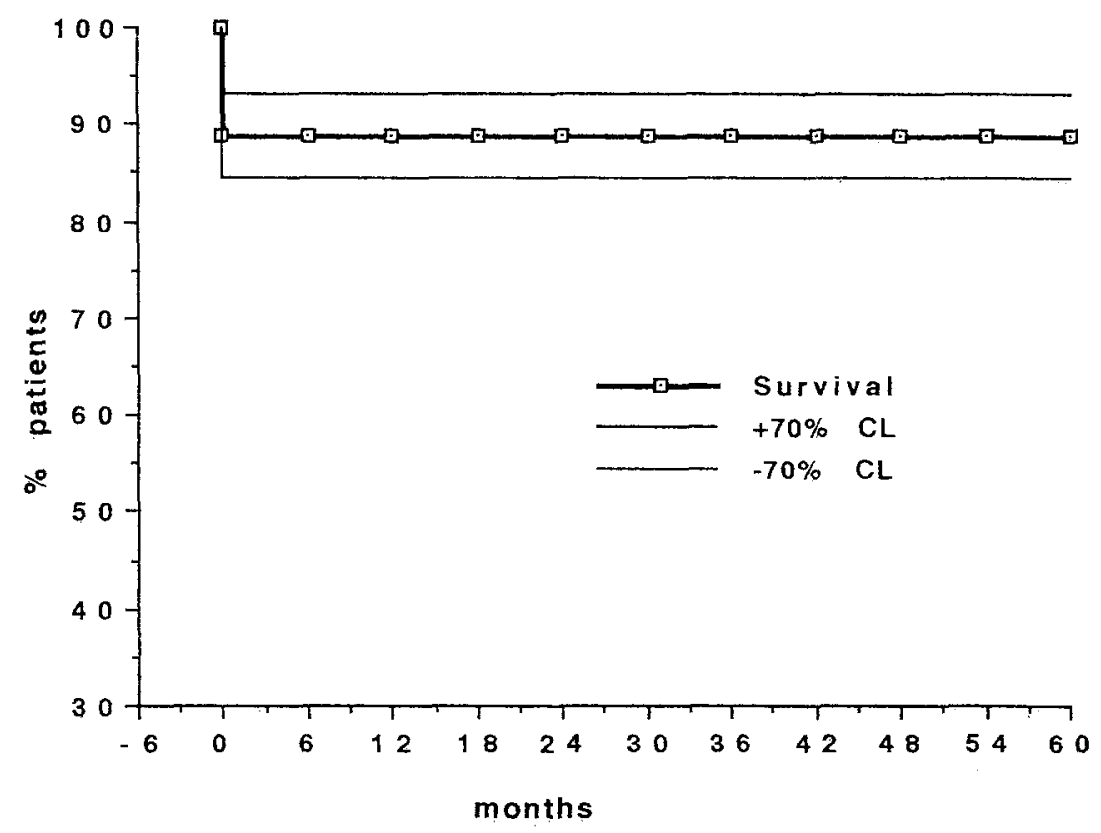

Fig. 4. Actuarial survival curve. $C L$, Confidence limits.

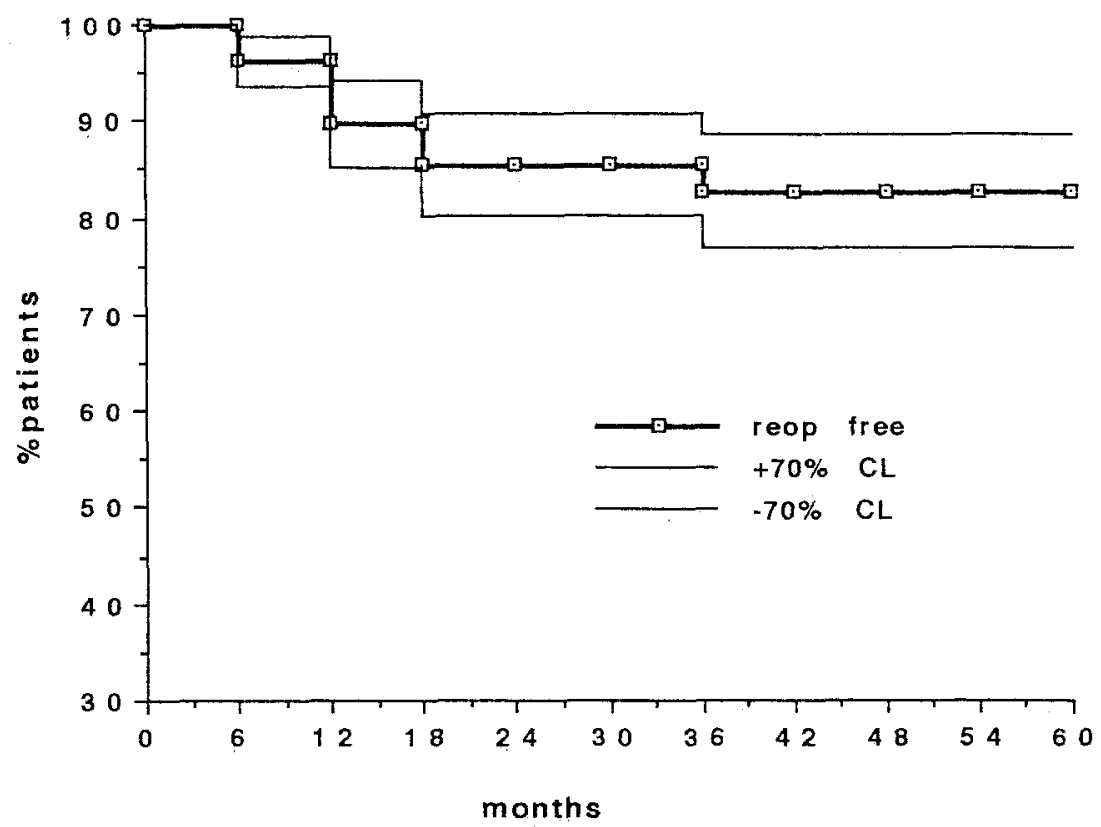

Fig. 5. Actuarial freedom from reoperation. $C L$, Confidence limits.

similar to that in other reports, ${ }^{9,14}$ was mostly due to the complex pathologic features, such as total anomalous pulmonary venous connection and atrioventricular valve regurgitation. We believe that the worse outcome during the years 1992 and 1993 could reflect our policy of extending the TECC operation to patients with more risk factors, emboldened perhaps by the very good results obtained during the first 3 years of our experience with the TECC technique. ${ }^{15}$ Failure of the TECC operation occurred mostly in patients with severe pulmonary artery stenosis or hypoplasia and a chronic volume 


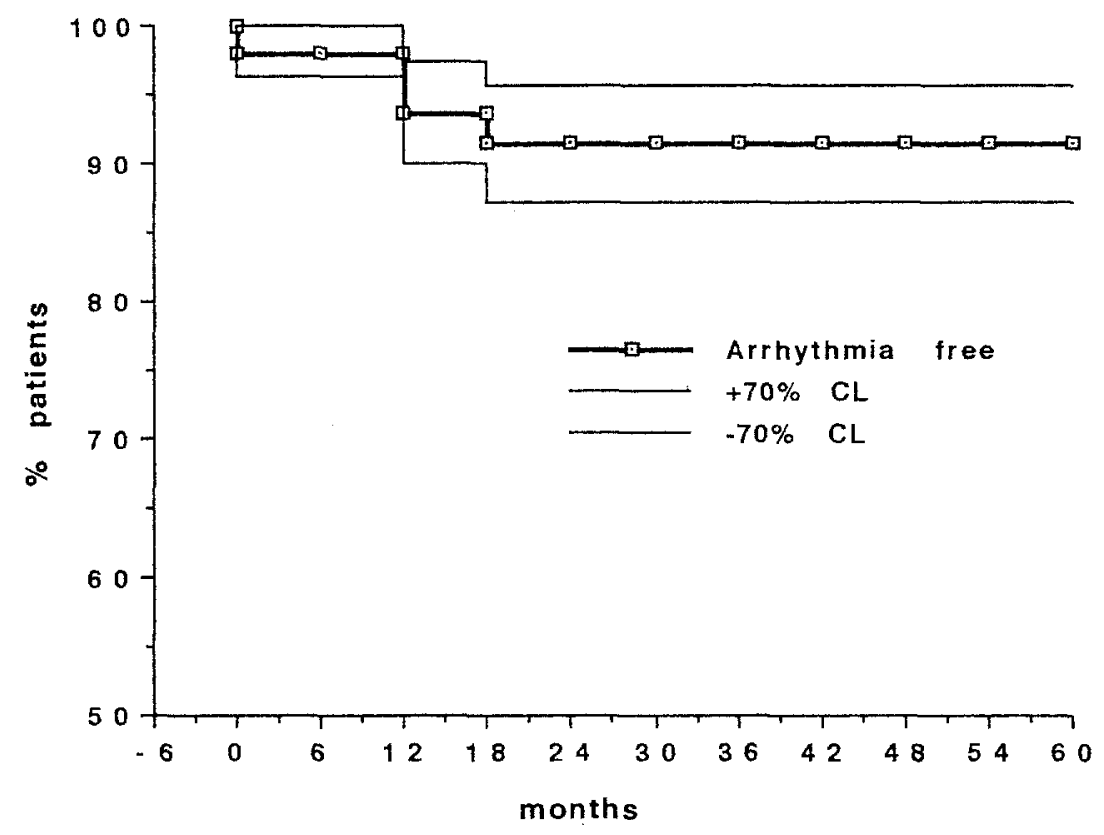

Fig. 6. Actuarial freedom from arrhythmia.

or pressure overload of the single ventricle resulting from age, long-standing systemic-pulmonary shunt, or atrioventricular valve regurgitation. The concept of staging Fontan-like operations in patients with complex congenital anomalies, including those with subaortic stenosis, by an intermediate BCPA treating at the same time the subaortic stenosis, has been well established ${ }^{16}$ : in fact, our results in that subset of patients support this policy. Several reports ${ }^{13,17,18}$ have documented that sudden reduction in total volume work of the single ventricle can result in rapid changes of ventricular geometry and increase in ventricular wall thickness. These changes may cause significant alterations in diastolic function with impaired filling of the ventricle. Hence more attention to ventricular geometry and dimensions in patients who are candidates for a Fontan-type repair should further improve surgical results. The increased risk of age younger than 4 years reported by several authors ${ }^{19,20}$ should be weighed against the deleterious effects of procedures that cause ventricular pressure or volume overload, myocardial hypertrophy, or pulmonary artery distortion. ${ }^{19-21}$ Because our results with the TECC operation in 16 patients under 4 years of age were very favorable, we continue to recommend the TECC operation in the younger age group. One other concern regarding the TECC technique is the risk of late conduit obstruction. Many reports dealing with prosthetic conduits in the venous circulation point out that obstruction occurs almost inevitably at some time. ${ }^{22,}{ }^{23}$ Nevertheless, most of these reports describe a mixed group of right heart conduits, valved or valveless, atriopulmonary or atrioventricular. Such conduits were usually placed in adverse hemodynamic conditions, for example, connected to a large atrium causing much turbulence and hence major risk of peel formation. Inasmuch as the TECC conduit relies on a more laminar hemodynamic flow pattern, there should be theoretically much less stimulus for peel formation. Unfortunately, very few of the largest reported series ${ }^{22,24,25}$ contain data on the fate of nonvalved Dacron conduits used for right atrial-pulmonary artery connections. Some centers reported long-term patency with right-sided conduits in patients who were treated with warfarin, aspirin, or dipyridamole. ${ }^{26,27}$ Our data show that the small reduction in mean caliber observed during the first 6 months after TECC does not progress over the following 5 years. Because the mechanism of peel thickening includes deposition of platelet-fibrin aggregates and thrombi between the peel itself and the conduit wall, ${ }^{23}$ the use of anticoagulants, as in our experience, should prevent or at least minimize progression of peel thickening. The maximal reduction in internal diameter measured in some patients was quantitatively important (around $1 / 3$ of the cross section) and is therefore cause for concern. Perhaps 
this reduction could be ascribed to changes in conduit shape, from circular to oval, which in turn could be the result of elongation of the conduits. Early in our experience, we made a concerted effort to minimize the amount of prosthetic material. This approach might have been ill advised, because a shorter conduit becomes more subject to incremental longitudinal stretching forces. More recently, we have changed to polytetrafluoroethylene conduits (rather than Dacron conduits) and to a longer size, hoping to decrease the incidence of changing conduit shape.

Atrial arrhythmias are common complications, particularly during late follow-up after the Fontan operation (up to $40 \%$ in some series). ${ }^{24,28,29}$ These arrhythmias are thought to be due to (1) scarring associated with suture lines, (2) stretching or damaging of the sinoatrial node area, (3) interference with its vascular supply during the cavopulmonary anastomosis, or (4) interference from high right atrial pressure and increased wall tension. Although the incidence of early and late arrhythmias appears to be somewhat less after TCPC than after other types of modified Fontan anastomoses, ${ }^{29-31}$ still a $20 \%$ incidence of atrial arrhythmias is significant. Nevertheless, with the technique of electrical flutter inducibility, the incidence of only $7.4 \%$ of midterm arrhythmias is promising. Avoiding intraatrial suture lines may be one of the explanations for these findings, as recently demonstrated in dogs by Rodefeld and coworkers. ${ }^{32}$ Our data so far suggest only a weak relationship between the occurrence of early versus late arrhythmias and also "longer" follow-up and late appearance of arrhythmias. The only patient who had both early and late arrhythmias had surgical damage to the cavoatrial junction at the time of the BCPA. The other three patients had common atrial distention owing to significant atrioventricular valve incompetence.

In conclusion, we believe that the TECC modification offers a simplified technique of right heart bypass and that it has the potential of reducing the risk of late atrial arrhythmias. Our initial concerns about possible conduit thrombotic obstruction, at least during this midterm follow-up, have been dispelled. At present we continue to use the TECC modification in all patients undergoing cavopulmonary bypass operations.

\section{REFERENCES}

1. Rodbard S. Wagner D. By-passing the right ventricle. Proc Soc Exp Biol Med 1949;71:59-70.
2. Carlon CA, Mondini PG, de Marchi R. Surgical treatment of some cardiovascular disease (new vascular anastomosis). J Int Coll Surg 1951;16:1-10.

3. Glenn WWL. Circulatory bypass of the right side of the heart: shunt between superior vena cava and distal right pulmonary artery. N Engl J Med 1958;259:117-20.

4. Fontan F, Mounicot FB, Baudet E, Simmoneau J, Gordo J, Gouffrant JM. "Correction" de l'atresie tricuspidienne. Rapport de deux cas "corriges" par l'utilization d'une technique chirurgicale nouvelle. Ann Chir Thorac Cardiovasc 1971;10: $39-47$.

5. Marcelletti C, Corno A, Giannico S, Marino B. Inferior vena cava-pulmonary artery extracardiac conduit: a new form of right heart bypass. J Thorac Cardiovase Surg 1990;100:228-32.

6. de Leval MR, Kilner P, Gewillig M, Bull C. Total cavopulmonary connection: a logical alternative to atriopulmonary connection for complex Fontan operation-experimental studies and early clinical experience. $\mathrm{J}$ Thorac Cardiovasc Surg 1988;96:682-95.

7. Jonas RA, Castaneda AR. Modified Fontan procedure: atrial baffle and systemic venous to pulmonary artery anastomotic techniques. J Cardiac Surg 1988;3:91-6.

8. Puga FJ, Chiavarelli M, Hagler DJ. Modification of the Fontan operation applicable to the patients with left atrioventricular atresia or single atrioventricular valve. Circulation 1987:76(Pt 2):53-60.

9. Knott-Craig CJ, Danielson GK, Schaff HV, Puga FJ, Weaver AL, Driscoll DD. The modified Fontan operation: analysis of risk factors for early postoperative death or takedown in 702 consecutive patients from one institution. J Thorac Cardiovase Surg 1995;109:1237-43.

10. Stein DG, Laks H, Drinkwater DC, Permut LC, Louie HW, Pearl JM, et al. Results of total cavopulmonary connection in the treatment of patients with a functional single ventricle. J Thorac Cardiovasc Surg 1991;102:280-7.

11. Mayer JE, Bridges ND, Lock JE, Hanley FL, Jonas RA, Castaneda AR. Factors associated with marked reduction in mortality for Fontan operation in patients with single ventricle. J Thorac Cardiovasc Surg 1992;103:444-52.

12. Jacobs ML, Norwood WI. Fontan operation: influence of modifications on morbidity and mortality. Ann Thorac Surg 1994;58:945-52.

13. Giannico S, Como A, Marino B, Cicini MP, Gagliardi MG, Amodeo $\mathrm{A}$, et al. Total extracardiac right heart bypass. Circulation 1992;86(Suppl):II110-7.

14. Culberston CB, George BL, Day RW, Laks H, Williams RG. Factors influencing survival of patients with heterotaxy syndrome undergoing the Fontan procedure. J Am Coll Cardiol 1992;20:678-84.

15. Amodeo A, Di Carlo DC, Di Donato RM, et al. Total extracardiac cavopulmonary connection for complex cardiac diseases [abstract]. Eighteenth Meeting of The Western Thoracic Surgical Association, Kawai, June 24-27, 1992.

16. Di Donato RM, Amodeo A, di Carlo D, Galletti L, Rinelli G, Pasquini L, et al. Staged Fontan operation for complex cardiac anomalies with subaortic obstruction. J Thorac Cardiovasc Surg 1993;105:398-405.

17. Sluymans T, Sanders SP, van der Velde M, Matitiau A, Parness I, Spevak PJ, et al. Natural history and patterns of recovery of contractile function in single left ventricle after Fontan operation. Circulation 1992;86:1753-61.

18. Chin AJ, Franklin WH, Andrews AA, Norwood WI. Changes 
in ventricular geometry early after the Fontan operation. Ann Thorac Surg 1993;56:1359-65.

19. Kirklin JK, Blackstone EH, Kirklin JW, Pacifico AD, Bargeron LM. The Fontan operation: ventricular hypertrophy, age, and date of operation as risk factors. J Thorac Cardiovasc Surg 1986;92:1049-64.

20. Bartmus DA, Driscoll DJ, Offord KP, et al. The modified Fontan operation for children less than 4 years old. J Am Coll Cardiol 1990;15:429-35.

21. Caspi J, Coles JG, Rabinovich M, Cohen D, Trusler GA, Williams WG, et al. Morphological findings contributing to a failed Fontan procedure: twelve-year experience. Circulation 1990;82(Suppl):IV177-82.

22. McGoon DC, Danielson GK, Puga FJ, Ritter DG, Mair DD, Ilstrup DM. Late results after extracardiac conduit repair for congenital cardiac defects. Am J Cardiol 1982:49:1741-9.

23. Agarwal KC, Edwards WD, Feldt RH, Danielson GK, Puga FJ, McGoon DC. Clinicopathological correlates of obstructed right-sided porcine-valved extracardiac conduits. J Thorac Cardiovasc Surg 1981;81:591-601.

24. Driscoll DI, Kenneth PO, Feldt HR, Schaff HV, Puga FJ, Danielson GD. Five to fifteen-year follow-up after Fontan operation. Circulation 1992;85:469-96.

25. Fernandez G, Costa F, Fontan F, Naftel DC, Blackstone EH, Kirklin JW. Prevalence of reoperation for pathway obstruction after Fontan operation. Ann Thorac Surg 1989;48:654-9.

26. Prenger KB, Hess IH, Cromme-Dijkhuis AH, Eijgelaar A. Porcine valved Dacron conduits in Fontan procedures. Ann Thorac Cardiovasc Surg 1988;46:526-30.

27. Laks H. Milliken JC, Perloff JK, Hellenbrand WE, George BL, Chin A, et al. Experience with Fontan procedure. J Thorac Cardiovasc Surg 1984;88:939-51.

28. Weber HS, Hellenbrand WE, Kleinman CS, Permutter RA, Rosenfeld LE. Predictors of rhythm disturbances and subsequent morbidity after the Fontan operation. Am J Cardiol 1989;64:762-7.

29. Gelatt M, Hamilton RM, McCrindle BW, Gow RM, Williams WG, Trusler GA, et al. Risk factors for atrial tachyarrhythmias after the Fontan operation. J Am Coll Cardiol 1994;24:1735-41.

30. Balaji S, Gewillig M, Bull C, de Leval MR, Deanfield JE. Arrhythmias after the Fontan procedure: comparison of total cavopulmonary connection and atriopulmonary connection. Circulation 1991;84(Suppl)III162-7.

31. Gewillig M, Wisk RK, de Leval RM, Deanfield JE. Early and late arrhythmia after the Fontan operation: predisposing factors and clinical consequences. Br Heart J 1992;67:72-9.

32. Rodefeld MD, Bromberg BI, Schluesser RB, Boineau JP, Cox JL, Huddleston CB. Atrial flutter after lateral tunnel construction in the modified Fontan operation: a canine model. J Thorac Cardiovasc Surg 1996;11:514-26.

\section{Discussion}

Dr. Leonard L. Bailey (Loma Linda, Calif.). Dr. Amodeo and his colleagues have been international leaders in the concept of extracardiac Fontan operations. As their experience expands, it becomes important for all of us to pay close attention to their outcomes, particularly in the long term.

Extracardiac routing of IVC blood flow to the pulmonary artery takes advantage of most of what we believe to be the best in Fontan reconstructive principles. It is simple, it is relatively safe in the short term, and it creates minimal atrial injury. The approach establishes rheologic patterns that conform to the suggestions of Marc de Leval and associates. Also, this approach reduces the temporal phenomenon of atrial distention and hypertrophy and thus may translate into a reduction of late atrial arrhythmias.

However, the extracardiac operations described by Dr. Amodeo are what I would consider complete, nonfenestrated Fontan operations. These operations are being performed at a time when many, if not most, centers are using so-called fenestrated Fontan operations as the definitive procedure. To stay trendy, one could connect the extracardiac tube to the pulmonary venous atrium either in a side-by-side fashion directly or with a small $\mathrm{H}$ graft.

The first question I have for Dr. Amodeo is this: Do you believe that the perioperative mortality and morbidity in this series could have been reduced by creating a fenestrated or H-graft connection from the extracardiac venous conduit to the pulmonary venous atrium in selected patients?

An additional long-term concern has to do with the low-velocity flow of blood in these conduits and ultimate conduit narrowing. Although there has not been shortterm concern about conduit narrowing, all of us have seen these conduits 10 and 12 years later, and they tend to calcify and obstruct ultimately, particularly the Dacron conduits.

Finally, my colleagues and I believe that the group from Rome has all the right principles in mind in the construction of the Fontan procedure. Where we take exception is in the use of a cylindric prosthetic graft to make the extracardiac connection from IVC to pulmonary arteries. My associate, Steven Gundry, has convinced me that in very nearly every case there is enough native pericardium with which to create an extracardiac in situ lateral tunnel that meets all of today's criteria for a good Fontan operation and requires no prosthetic material. In addition, Dr. Gundry's technique permits fenestration, if desired during the operation or later in the cardiac catheterization laboratory, if the patient is a marginal candidate (like many of the patients that you described) for Fontan physiology. We have used the extracardiac autologous pericardial tunnel, the so-called lateral tunnel, for the last 18 completion Fontan operations performed at the Children's Hospital, Loma Linda University. None has been fenestrated. Early restudy of this recent innovation suggests that the approach has real promise. I am sure that Dr. Gundry will talk more about that in months to come.

Dr. Amodeo. Regarding the first question, I agree with you that now we have in our armamentarium the fenestration that could be incorporated as a direct anastomosis or as a small tube graft between the conduit and the atrium. I also agree with you that a fenestration probably could reduce the early mortality and morbidity in patients in whom the risk is high. In the future our patients probably will benefit from this modification.

The second question raises some concerns related to the conduit in the venous system, especially Dacron conduits. If we look carefully at the literature, we find that most 10- to 15-year follow-up data reported include conduits in the worst hemodynamic and hydrodynamic 
conditions. As the conduit interposed between the IVC and the pulmonary arteries relies on a better hydrodynamic pattern with uniform caliber through the pathway and less turbulence, we can speculate, and actually we are observing in this follow-up, that there could be less chance for obstruction. Some centers report good patency of rightsided conduits in patients treated with warfarin or aspirin. Our current policy is to use warfarin for the first 6 months and then move to aspirin. Of course, a longer follow-up will be needed to assess the late fate of this conduit.

Dr. V. Mohan Reddy (San Francisco, Calif.). I have one question. Inasmuch as these conduits do not have any growth potential, is there any age preference now for when this operation should be done? If the patient is very young, do you still choose to use some other technique, or do you prefer to wait longer before you do this extracardiac conduit Fontan procedure?

Dr. Amodeo. There is no set preferential age for performing the extracardiac Fontan operation. Of course, because a lot of patients of this series received multiple previous palliative procedures and most of them have undergone staging with a BCPA, they can easily reach an age of 3 to 4 years. At this age a conduit can be inserted easily between 20 and 24 that is not far from the size of an adult IVC. Young age in our patients is not predictive for early failure. Our major concern at the beginning of the experience was related to the amount of prosthetic material (Dacron and successively polytetrafluoroethylene): for that reason, we tailored the conduit as short as possible in an effort to reduce the incidence of obstruction and thromboembolism. This could be the reason for the conduit shape anomalies that we are seeing in our magnetic resonance imaging follow-up. We actually have increased the length of the conduits, making them less susceptible to longitudinal stretching forces related to child growth. If this is indeed the principal mechanism of late obstruction, we could proceed as we did in a patient who was admitted to the hospital just 1 month ago. Magnetic resonance imaging showed that the conduit was obstructed more than $50 \%$ at the level of the distal anastomosis. We treated this patient by putting a stent in the conduit. An angiogram taken after stent implantation shows a normal diameter. This may suggest that the mechanism of stenosis was not the accumulation of thrombotic material but an elongation and distortion of the conduit. 